\title{
Analysis and Formation of Hazardous Substances from Surfactant-Grafted Polyacrylamide Powder for Oilfield Production
}

\author{
Tingting Jiang1, Haiyu Wang2, Baohui Wang1 \\ ${ }^{1}$ Institute of New Energy Chemistry and Environmental Science, College of Chemistry \& Chemical Engineering, \\ Northeast Petroleum University, Daqing, China \\ ${ }^{2}$ First Oil Plant, Daqing Oilfield Company Limited, Daqing, China \\ Email: jiangtingting82@163.com
}

Received 12 June 2014; revised 27 July 2014; accepted 11 August 2014

Copyright $@ 2014$ by authors and Scientific Research Publishing Inc.

This work is licensed under the Creative Commons Attribution International License (CC BY).

http://creativecommons.org/licenses/by/4.0/

(c) () Open Access

\begin{abstract}
Surfactant-grafted Polyacrylamide (S-PAM) serves as a kind of economical and efficient flooding agents for its single component in the enhanced oil recovery in Daqing oilfield in China. The oil displacement experiments using S-PAM in multi-blocks revealed that in-use S-PAMs differ greatly from ordinary polymers. Aiming at making clear hazardous substances of S-PAM powder, this study characterized two commonly used S-PAMs in oil field through chemical analysis and instrumental analysis, and analyzed the toxic and hazardous gases of the two S-PAM powders.
\end{abstract}

\section{Keywords}

Surfactant-Grafted Polyacrylamide, Hazardous Substances, Oilfield

\section{Introduction}

The Enhanced Oil Recovery (EOR) techniques have widely been used in oilfields, which mainly include the polymer flooding (PAM), SP flooding (Polymer-Surfactant) and ASP flooding (Alkali-Polymer-Surfactant). There are varied degrees of problems in the application of the above flooding, such polymer flooding remains high interfacial tension between the fluid and crude oil, basically no solubilization and emulsification capacity for crude oil, no polymer with the anti-salt, anti-bacterial and anti-oxidation function, and no preparation with sewage. The components of chemicals in Binary or ternary chemical flooding have quite difference in the diffu- 
sion and migration in the reservoir, exhibited in the "chromatographic effect” while no "synergies effect”, results in the low enhanced oil recovery. In addition, the strong base additives also led to the severe scaling in many facilities during the recovery operation. Therefore, there are some inconveniences to the production [1][3].

A new type of compound has been required for the above reason. Generally, basic polyacrylamide (PAM), which is simple, long and repeated chain $\left(\mathrm{CH}_{2}-\mathrm{CH}_{2}-\mathrm{CONH}_{2}\right)$ polymer with the appropriate stability, is employed for the popular polymer flooding. Recently, Surfactant-grafted Polyacrylamide (Referred to as S-PAM), which combines the advantages of polymer and surfactant, has been developed for the field test. It collects the advantages of enhancing the anti-shearing, reducing the flow ratio, expanding the sweep efficiency, reducing the interfacial tension, improving the solubilization and emulsifying capacity, etc. [4]-[7].

Relevant data reveal that Surfactant-grafted Polyacrylamide (S-PAM) has a framework constituted by ordinary polyacrylamide hydrocarbon chains. By grafting and copolymerizing the functional monomers and functional group to the lateral groups of the molecular chains, the original polymer hydrocarbon chains can be converted into the hydrocarbon chains containing a large number of surfactants. Therefore, the aqueous solution of S-PAM is provided with the physical and chemical properties of the polymer and surfactant, as well as the new properties which are absent in the two agents. Generally, surfactant reduces the interfacial tension between oil and water in oil-water two-phase system to improve oil displacement efficiency. The S-PAM disperses the nonpolar substances in non-water system (including crude oil, coal power, cement, pigment, and so on) into emulsion and thus overcomes the application limitations of conventional surfactants in non-aqueous system.

The oil displacement experiments using S-PAM in multi-blocks revealed that in-use S-PAMs differ greatly from ordinary polymers. Based on the structure, chemical properties and manufacturing technique, small molecule volatile gases may be adsorbed in the surface of S-PAM, such as $\mathrm{H}_{2} \mathrm{~S}, \mathrm{HCl}, \mathrm{SO}_{2}, \mathrm{HCHO}, \mathrm{NH}_{3}, \mathrm{Cl}_{2}, \mathrm{HF}_{\mathrm{C}} \mathrm{CO}$, $\mathrm{NO}_{2}, \mathrm{O}_{3}, \mathrm{PH}_{3}$, etc. This study detected gases release of two commonly used S-PAM powders in oil field through chemical analysis and instrumental analysis methods.

\section{Experimental}

\subsection{Materials and Instruments}

Two origins of S-PAM were used in this experiment: Daqing Refining \& Chemical Company S-PAM (Lianhua type III), which is called Lianhua S-PAM; Shanghai Haibo company S-PAM (Haibo type III), which is called Haibo S-PAM; The main instruments have ammonia gas meter (Z-800), Formaldehyde gas sensor (Formaldemeder-htv) and multigases detector (USA).

\subsection{Identification Methods and Principles of Hazardous Gases}

Two S-PAM powders in the plastic wrap sealed containers were prepared for measurement respectively. The gases were measured by the sensors of detectors which were inserted into the glass container from a hole of plastic wrap, or imported into the solution by needle. Gases emissions of two S-PAM powders were measured at room temperature respectively. The highest content of gases was measured, which was converted to mass of gas evolution per gram of solid S-PAM.

\subsubsection{Identification of Formaldehyde}

Gases emissions of two S-PAM powders within the container were measured by Formaldehyde gas sensor (Formaldemeder-htv) at room temperature respectively.

\subsubsection{Identification of Ammonia}

Ammonia emissions of two S-PAM powders within the container were measured by ammonia gas meter (Z-800) at room temperature respectively.

\subsubsection{Identification of Hydrogen Sulfide}

The principle is that hydrogen sulfide and copper sulfate solution generated a black precipitate, then $\mathrm{H}_{2} \mathrm{~S}$ was detected. 


$$
\mathrm{H}_{2} \mathrm{~S}+\mathrm{CuSO}_{4}=\mathrm{CuS} \downarrow+\mathrm{H}_{2} \mathrm{SO}_{4}
$$

Gases emissions of two S-PAM powders within the container were imported into the copper sulfate solution, at room temperature, and the phenomenon was observed repeatedly to see whether a black precipitate (CuS) formed.

\subsubsection{Identification of Hydrogen Chloride}

The principle is that white precipitate is produced by the reaction of hydrogen chloride with silver nitrate, and then $\mathrm{HCl}$ was detected.

$$
\mathrm{Ag}^{+}+\mathrm{Cl}^{-}=\mathrm{AgCl} \downarrow
$$

Gases emissions of two S-PAM powders within the container were imported into the silver nitrate solution, at room temperature, and the phenomenon was observed repeatedly to see whether a white precipitate $(\mathrm{AgCl})$ formed.

\subsubsection{Identification of Sulfur Dioxide}

The principle is that sulfur dioxide solution can make magenta fade, and then $\mathrm{SO}_{2}$ was detected.

Gases emissions of two S-PAM powders within the container were imported into magenta solution (diluted), and the phenomenon was observed repeatedly to see whether magenta faded.

\subsubsection{Identification of Hydrogen Phosphide}

The principle is that different concentrations of phosphine gas in case of silver nitrate generated light brown or dark brown silver phosphate, which emerged light brown or dark brown precipitate $\left(\mathrm{Ag}_{3} \mathrm{P}\right)$, then $\mathrm{PH}_{3}$ was detected.

$$
\mathrm{PH}_{3}+3 \mathrm{AgNO}_{3}=\mathrm{Ag}_{3} \mathrm{P} \downarrow+3 \mathrm{HNO}_{3}
$$

Gases emissions of two S-PAM powders within the container were imported into the silver nitrate solution at room temperature, and the phenomenon was observed repeatedly to see whether a light brown or dark brown precipitate $\left(\mathrm{Ag}_{3} \mathrm{P}\right)$ formed.

\subsubsection{Identification of Other Gases}

Gases emissions of two S-PAM powders within the container were measured directly by multigases detector (USA) at room temperature for the presence of $\mathrm{Cl}_{2}, \mathrm{HF}, \mathrm{CO}, \mathrm{NO}_{2}, \mathrm{O}_{3}$, etc.

\section{Results and Discussion}

\subsection{Identification Results of Gases}

Chemical methods and instruments were used the above method for qualitative identification, detecting the presence of $\mathrm{H}_{2} \mathrm{~S}, \mathrm{HCl}, \mathrm{SO}_{2}, \mathrm{HCHO}, \mathrm{NH}_{3}, \mathrm{Cl}_{2}, \mathrm{HF}, \mathrm{CO}, \mathrm{NO}_{2}, \mathrm{O}_{3}, \mathrm{PH}_{3}$, etc. Gases emissions of two S-PAM powders were measured at room temperature respectively. The highest content of gases was measured, which was converted to mass of gas evolution per gram of S-PAM powder. The test results were shown in Table 1.

Through qualitative identification of two S-PAM powders for eleven gases, only ammonia was detected.

\subsection{Mechanism of Ammonia Release}

S-PAM is Surfactant-grafted PAM, the structure and nature of which show some changes after grafted. Pyrolysis reaction of PAM has been adequately studied under the thermal effect. The powder PAM is thermally stable below $200^{\circ} \mathrm{C}$, which has only slight loss of quality in a relatively short period of time. The mass loss is mainly due to loss of adsorbed water or other volatile impurities. Pendant groups of PAM exploded over $200^{\circ} \mathrm{C}-220^{\circ} \mathrm{C}$. Then molecular chain of PAM breaks at higher temperatures. PAM is easily hydrolyzed at lower temperature $\left(40^{\circ} \mathrm{C}-60^{\circ} \mathrm{C}\right)$ in alkaline conditions. Acidic hydrolysis of PAM is required high temperatures, which is slower than the alkaline hydrolysis [8]. According to previous experiments, the ammonia release of powder S-PAM was measured at room temperature to $80^{\circ} \mathrm{C}$. And ammonia release of S-PAM solution was measured at room temperature. The chemical components and stereo structure should be modified in the some extension after the basic PAM is grafted. The harmful ammonia gas was generated during the operation of S-PAM or high temperature. 
Table 1. Test results of toxic and hazardous gases.

\begin{tabular}{cccc}
\hline & & & Test results \\
\cline { 3 - 4 } & $\mathrm{Gas}$ & Lianhua S-PAM & Haibo S-PAM \\
\hline 1 & $\mathrm{H}_{2} \mathrm{~S}$ & Undetected & Undetected \\
2 & $\mathrm{HCl}$ & Undetected & Undetected \\
3 & $\mathrm{SO}_{2}$ & Undetected & Undetected \\
4 & $\mathrm{HCHO}$ & Undetected & Undetected \\
5 & $\mathrm{NH}_{3}$ & $2.76 \mathrm{mg} / \mathrm{g}$ & 2.38 mg/g \\
6 & $\mathrm{Cl}_{2}$ & Undetected & Undetected \\
7 & $\mathrm{HF}_{8}$ & Undetected & Undetected \\
9 & $\mathrm{CO}_{10}$ & Undetected & Undetected \\
11 & $\mathrm{NO}_{2}$ & Undetected & Undetected \\
\hline
\end{tabular}

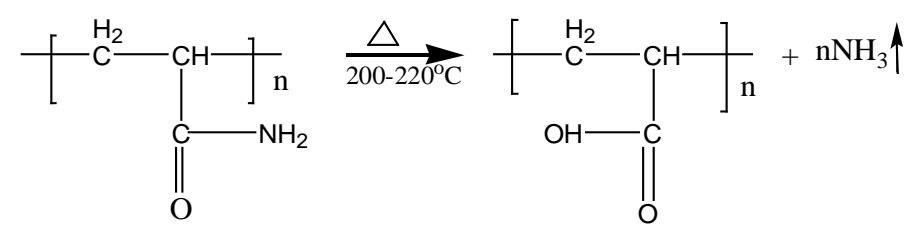

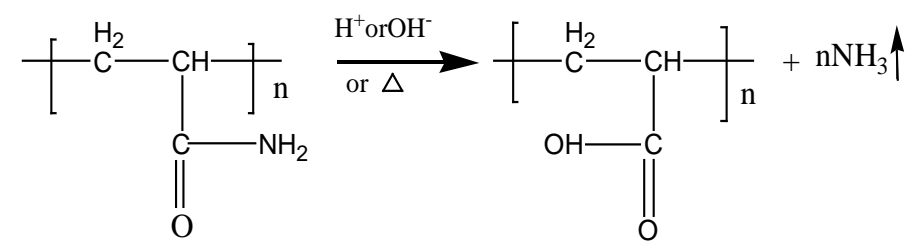

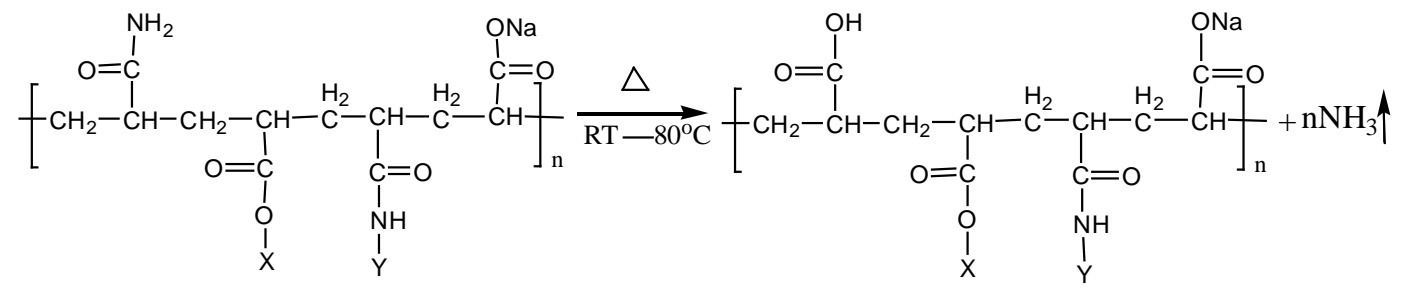

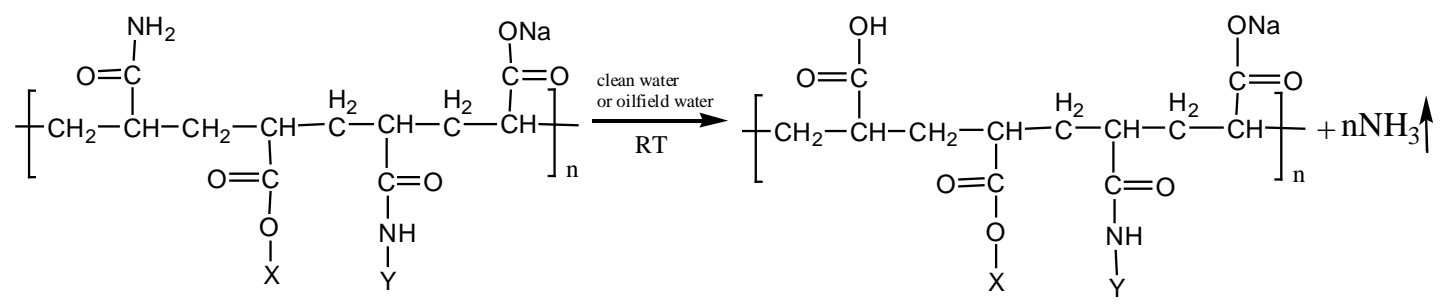

\section{Conclusion}

Through qualitative identification of two S-PAM powders for eleven gases, only ammonia was detected; $\mathrm{H}_{2} \mathrm{~S}$, $\mathrm{HCl}, \mathrm{SO}_{2}, \mathrm{HCHO}, \mathrm{Cl}_{2}, \mathrm{HF}, \mathrm{CO}, \mathrm{NO}_{2}, \mathrm{O}_{3}, \mathrm{PH}_{3}$ were not detected. 


\section{References}

[1] Ge, G.Z., Wang, J.Y. and Wang, Y.L. (2001) Polymer Flooding and Related Chemical Flooding Progress. Oilfield Chemistry, 18, 282-284. (In Chinese)

[2] Wang, D.M., Xia, H.F., Liu, Z.C., et al. (2001) Study of the Mechanism of Polymer Solution with Viscoelastic Behaviour Increasing Microscopicoil Displacement Efficiency and the Forming of Steady “Oil Thread” Flow Channel. SPE68732. The Society of Petroleum Engineers.

[3] Chen, G. (1997) The Strategic Position of Three Oil Production in the Oil Industry in Development. Energy of China, 9, 17-19. (In Chinese)

[4] Gang, Q.L. (1998) A Dissertation on Chinese Tertiary Recovery Technology. OGRT, 5, 1-7. (In Chinese)

[5] Hizal, G., Tunca, U., Yagci, Y., et al. (2006) Anthracene-Maleimide-Based Diels-Alder “Click Chemistry” as a Novel Route to Graft Copolymers. Macromolecules, 39, 5330-5336. http://dx.doi.org/10.1021/ma060690c

[6] Wang, Y.M., Wang, Y.J. and Lu, X.B. (2008) “Grafting-From” Polymerization for Uniformly Bulk Modification of Pre-Existing Polymer Materials via a Supercritical-Fluid Route. Polymer, 49, 474-480. http://dx.doi.org/10.1016/j.polymer.2007.11.028

[7] Zhao, J.R., Li, J.Y., Feng, Y., et al. (2007) A Novel Approach to Synthesis of Functional CPVC and CPE or Graft Copolymers-In Situ Chlorinating Graft. Polymers for Advanced Technologies, 18, 822-828. http://dx.doi.org/10.1002/pat.941

[8] Fang, D.B. (2006) Acrylamide Polymers. Chemical Industry Press, Beijing, 58-84. (In Chinese) 
Scientific Research Publishing (SCIRP) is one of the largest Open Access journal publishers. It is currently publishing more than 200 open access, online, peer-reviewed journals covering a wide range of academic disciplines. SCIRP serves the worldwide academic communities and contributes to the progress and application of science with its publication.

Other selected journals from SCIRP are listed as below. Submit your manuscript to us via either submit@scirp.org or Online Submission Portal.
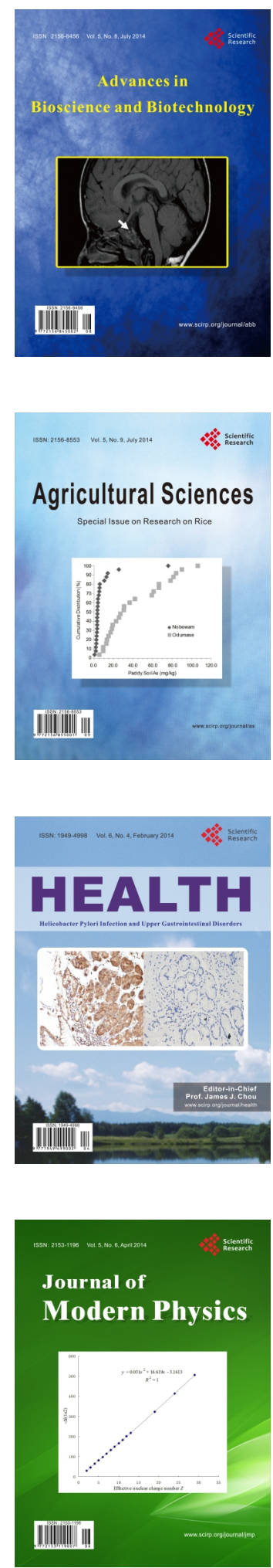
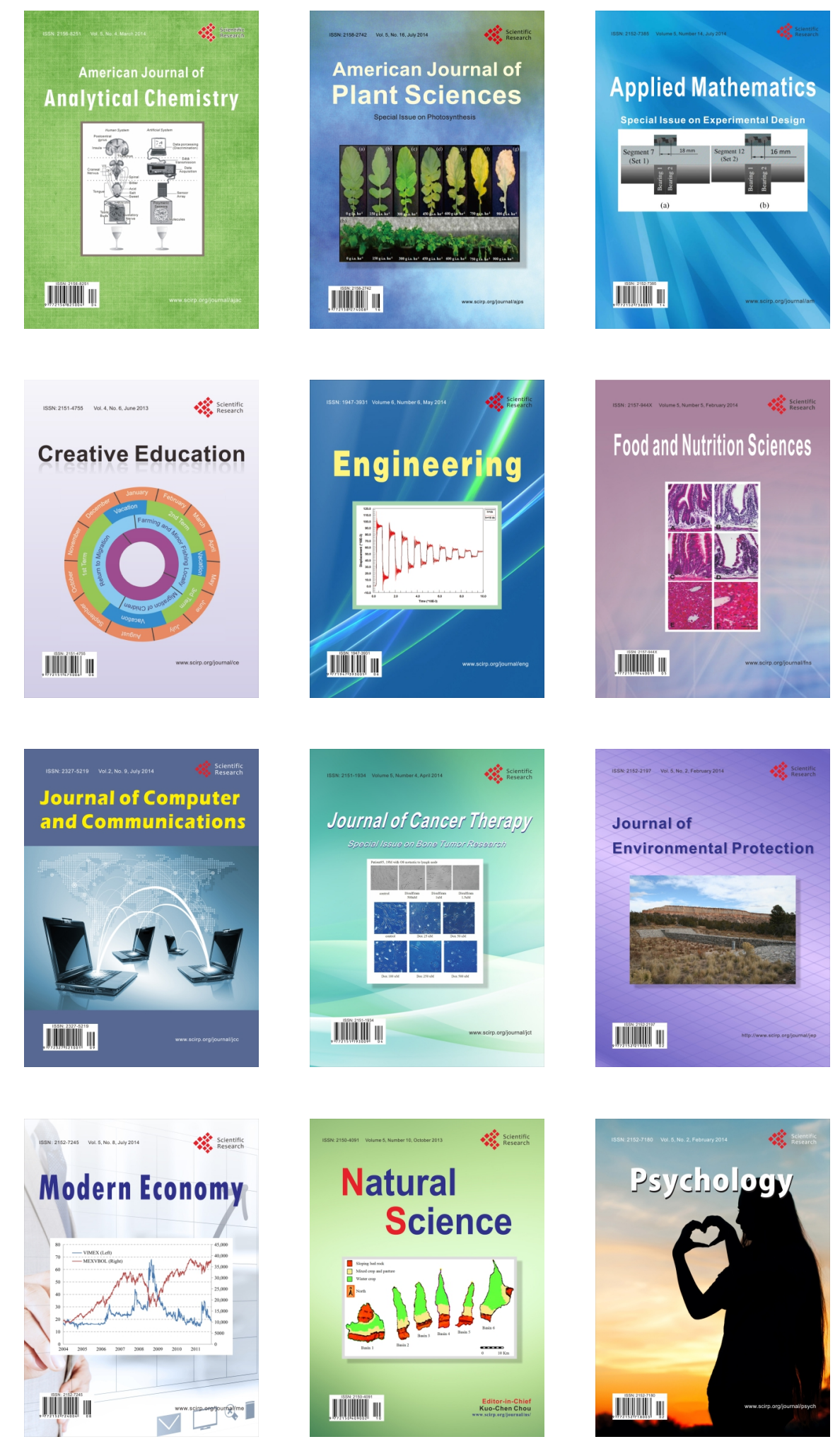